\title{
Advance care planning in severe COPD: it is time to engage with the future
}

\author{
Stefan Andreas ${ }^{1,2}$ and Bernd Alt-Epping ${ }^{3}$ \\ ${ }^{1}$ Cardiology and Pneumology, University Medical Center Göttingen, Göttingen, Germany. ${ }^{2}$ Lung Clinic \\ Immenhausen, Immenhausen, Germany. ${ }^{3}$ Dept of Palliative Medicine, University Medical Center Göttingen, \\ Göttingen, Germany.
}

Correspondence: Stefan Andreas, Abteilung Kardiologie und Pneumologie, Universitätsmedizin Göttingen, Robert Koch Str. 40, 37075 Göttingen, Germany. E-mail: stefan.andreasamed.uni-goettingen.de

@ERSpublications

Advance care planning should be part of our clinical routine in severe COPD http://ow.ly/Cshs30i8FS9

Cite this article as: Andreas S, Alt-Epping B. Advance care planning in severe COPD: it is time to engage with the future. ERJ Open Res 2018; 4: 00009-2018 [https://doi.org/10.1183/23120541.000092018].

Severe chronic obstructive pulmonary disease (COPD) is a progressive and debilitating illness characterised by relentless loss of function, intensifying dyspnoea and frequent exacerbations. COPD patients are evidently at increased risk of depression, frailty and death [1,2]. Predicting individual short-term prognosis and course of events is difficult if not impossible.

While many COPD patients receive costly therapy during acute exacerbations, they often get lost between acute secondary care and primary care and receive little emotional and social support [3]. This is different from what is implemented in patients with cancer, where end-of-life care conversations, advance care planning and palliative care are more established and have already become a mainstay of cancer care. In this context we should keep in mind that COPD patients experience severe morbidity for a longer period of time than cancer patients [4], and suffer even more from impaired activities of daily living, impaired physical, social and emotional functioning, and more from anxiety and depression than patients with nonsmall cell lung cancer [5]. Additionally, dyspnoea is subjectively perceived as being as severe and life-threatening as pain, and the central processing of perceived pain as well as dyspnoea in the limbic system is quite similar [6].

We do not know many details about the healthcare needs of patients suffering from end-stage COPD [7]. COPD patients have a poor understanding of COPD as a life-limiting disease and are less likely to realise that death is imminent [4]. Patients with end-stage COPD were found not to actively express a wish for help because they do not consider their limitations to be abnormal and because they do not realise that there are possibilities to improve their situation [7]. However, even physicians hesitate to discuss these issues, fearing that they are destroying hope for recovery or are unable to spend precious time in a demanding emotional encounter with severely ill patients and/or their family, and therefore tend to delay prognostic conversations and end-of-life discussions until the event that should have been anticipated has occurred $[4,8]$. Thus, the demand of the scientific community to communicate in a timely manner and implement do-not-resuscitate (DNR) orders in patients with severe COPD does not necessarily find immediate, self-evident acceptance in clinical practice [8].

In this issue of ERJ Open Research, RASKIN et al. [9] reported the first comprehensive analysis on DNR order implementation in COPD patients. To this end, the Leuven COPD cohort, a tertiary care hospital cohort consisting of 569 COPD patients with an age $>50$ years and a post-bronchodilator forced expiratory

Received: Jan 122018 | Accepted: Jan 142018

Conflict of interest: None declared.

Copyright $\odot$ ERS 2018. This article is open access and distributed under the terms of the Creative Commons Attribution Non-Commercial Licence 4.0. 
volume in $1 \mathrm{~s}\left(\mathrm{FEV}_{1}\right) /$ forced vital capacity ratio $<0.7$, was evaluated. The retrospective analysis with a follow-up of $2.5-8$ years revealed that 345 patients (61\%) had no written form that would describe the patient's individual therapeutic preferences with respect to end-of-life care (DNR order). Of those 345 patients, 27\% died during a median follow-up of 1935 days. 194 patients (39\%) had a DNR order, of whom 17 had a DNR order at baseline, and $82 \%$ eventually died (median follow-up 528 days). Of the 177 patients receiving a DNR order during follow-up, 76\% died (median follow-up 1322 days). Nearly all of the DNR orders were implemented during hospitalisation. The most frequent statement in DNR orders was "no cardiopulmonary resuscitation nor intubation, noninvasive ventilation (NIV) to be considered". Age, FEV1, oxygen dependency and previous mechanical ventilation were strong independent predictors of a DNR order.

What is clinically relevant from this wealth of data? In accord with the authors we have to notice a discrepancy between evidence and recommendations on one side and the presented real-world data on the other side. While guidelines recommend engagement in advance care planning in the early stages of a disease (and provide abundant evidence for its effectiveness in terms of realising patient preferences), and advise against making end-of-life decisions during hospitalisation, the majority of DNR orders were found to be implemented during hospitalisation.

Advance care planning is a process of thinking about, discussing, planning and documenting therapeutic preferences for hypothetical scenarios where the patient cannot express his/her own will. This process is conducted by the patient, his/her family or healthcare attorney, his/her physician or an advance care planning facilitator. Advance care planning has numerous, well-described positive effects on end-of-life care for patients, such as reductions in futile life-sustaining treatments and increased compliance with patient preferences [4].

Failure to discuss life-prolonging interventions or therapeutic restrictions at the end of life should be avoided as it will result in more patient suffering [10]. Indeed, RASKIN et al. [9] reported that all seven patients without a DNR admitted to the intensive care unit died on mechanical ventilation, although only two were admitted for respiratory reasons. This underscores the notion that COPD patients receive less palliative and end-of-life care [5].

Guidelines emphasise communication with the patients while establishing and continuing NIV [11]. This holds especially true when a change of the therapeutic aim is discussed. Accordingly, it is recommended that clinicians delivering NIV or invasive mechanical ventilation should have ready access to palliative medicine and consider advance care planning. On the basis of moderate certainty of evidence, the recent European Respiratory Society/American Thoracic Society clinical practice guidelines on NIV for acute respiratory failure suggest that, following appropriate patient selection, NIV is an option in severely dyspnoeic patients for palliation in the setting of terminal cancer or other terminal conditions [12].

How can we use the above in our clinical routine? First, we need more awareness that, in the majority of cases, severe chronic lung disease like COPD will finally terminate the patient's life, and that dying from lung disease is an expected outcome. Secondly, this insight should trigger communication with the patient and his/her family about the general therapeutic attitude, how to proceed in emergency scenarios, who could express the patient's preferences if he/she cannot do so, and about other end-of-life preferences [13]. Thirdly, we are all aware of the more unpredictable course of COPD and other non-cancer disease as opposed to, for instance, advanced metastatic solid cancer. But then, even more, sensitive communication about both favourable and unfavourable outcomes and scenarios will be required, in order to prevent undue expectations and demands. Fourthly, palliative care is a support concept for any patients in need, not only for cancer patients, and it might be worthwhile considering involving specialised palliative care services early in the course of the disease. However, good communication, the principles of advance care planning, and basic and anticipatory symptom control (put simply, "engaging with the upcoming") should be the competence and responsibility of any speciality involved in the care of patients suffering from lung disease.

William Shakespeare wrote in 1600: "But I must go and meet with danger there, Or it will seek me in another place And find me worse provided" (Henry IV, Part 2). In this respect, the survey by Raskin et al. [9] has hopefully triggered an overdue discussion about the urgent need to "meet with danger", in order to be better provided for crises and emergencies, and to better integrate basic palliative principles into pneumology.

\section{References}

1 Lahousse L, Ziere G, Verlinden VJ, et al. Risk of frailty in elderly with COPD: a population-based study. J Gerontol A Biol Sci Med Sci 2016; 71: 689-695.

2 Andreas S, Batra A, Behr J, et al. Tabakentwöhnung bei COPD [Smoking cessation in patients with COPD]. Pneumologie 2014; 68: 237-258. 
3 Momen N, Hadfield P, Kuhn I, et al. Discussing an uncertain future: end-of-life care conversations in chronic obstructive pulmonary disease. A systematic literature review and narrative synthesis. Thorax 2012; 67: 777-780.

4 Narsavage GL, Chen YJ, Korn B, et al. The potential of palliative care for patients with respiratory diseases. Breathe 2017; 13: 278-289.

5 Gore JM, Brophy CJ, Greenstone MA. How well do we care for patients with end stage chronic obstructive pulmonary disease (COPD)? A comparison of palliative care and quality of life in COPD and lung cancer. Thorax 2000; 55: 1000-1006.

6 von Leupoldt A, Sommer T, Kegat S, et al. The unpleasantness of perceived dyspnea is processed in the anterior insula and amygdala. Am J Respir Crit Care Med 2008; 177: 1026-1032.

7 Habraken JM, Willems DL, de Kort SJ, et al. Health care needs in end-stage COPD: a structured literature review. Patient Educ Couns 2007; 68: 121-130.

8 Smith TA, Disler RT, Jenkins CR, et al. Perspectives on advance care planning among patients recently requiring non-invasive ventilation for acute respiratory failure: a qualitative study using thematic analysis. Palliat Med 2017; 31: 566-574.

9 Raskin J, Vermeersch K, Everaerts S, et al. Do-not-resuscitate orders as part of advance care planning in patients with COPD. ERJ Open Res 2018; 4: 00116-2017.

10 Claessens MT, Lynn J, Zhong Z, et al. Dying with lung cancer or chronic obstructive pulmonary disease: insights from SUPPORT. Study to Understand Prognoses and Preferences for Outcomes and Risks of Treatments. J Am Geriatr Soc 2000; 48: Suppl. 5, S146-S153.

11 Windisch W, Dreher M, Geiseler J, et al. S2k-Leitlinie: Nichtinvasive und invasive Beatmung als Therapie der chronischen respiratorischen Insuffizienz - Revision 2017 [Guidelines for non-invasive and invasive home mechanical ventilation for treatment of chronic respiratory failure - update 2017]. Pneumologie 2017; 71: 722-795.

12 Rochwerg B, Brochard L, Elliott MW, et al. Official ERS/ATS clinical practice guidelines: noninvasive ventilation for acute respiratory failure. Eur Respir J 2017; 50: 1602426.

13 Nauck F, Alt-Epping B. Crises in palliative care - a comprehensive approach. Lancet Oncol 2008; 9: 1086-1091. 